Tolulope Akinseye ${ }^{1}$

DOI: 10.31902/LL.2019.7.5

\title{
THEMATIC SELECTION AND PROGRESSION PATTERNS IN L2 THESES ABSTRACTS FROM HUMANITIES AND SCIENCE
}

\begin{abstract}
This paper discusses the internal logico-relations of the theses abstracts from humanities and science, written in English as a second language (ESL). A research abstract is an academic text designed to attract and get the readers to read the research study which it summarises; thus, the coherence of ideas presented in it presumably affects the possible evaluations from the readers. Previous studies have examined the Theme/Rheme constructs as important cohesive elements at the level of discourse, with less attention to the sentential analysis of the thematic selection and the progression patterns in second language (L2) theses abstracts. Therefore, this paper aims at investigating and comparing the thematic markedness and its progression patterns as sources of the cohesive information in L2 humanities and science theses abstracts. In this paper, $60 \mathrm{PhD}$ theses abstracts from the Premier University, Nigeria, are analysed. Quantitative and qualitative methods of analysis are applied. The abstracts from humanities and sciences (30 abstracts each) were purposefully selected and syntactically analysed, in terms of the Systemic Functional Linguistics' model of textual metafunction. The findings show that the theme unmarkedness, as well as the constant theme progression pattern, prevail in the two disciplines, although they feature varying frequencies.

Key words: academic writing, theses abstracts, theme markedness, theme/rheme, progression pattern
\end{abstract}

\section{Introduction}

Academic writing is an art recognized as difficult for second language speakers of the English language. Although academic discourse is considered to be objective and unbiased, the social involvement and the relationship between the writer and the readers and, in particular, second language writers across disciplines, deserve extensive examination. In formal writing, particularly that of scholars, it is generally required that a text must pass the test of cohesion and coherence, which Halliday and Hassan called the relation of meaning within a text (1976: 4). Systemic Functional Grammar is concerned with the textual metafunction, one of the three metafunctions of language, which specifically focuses on the organization of text. A sentential analysis of the thematic structure was used to identify and classify the thematic selection (in terms of the markedness and unmarkedness choices) in the selected abstracts, while a discourse analysis was employed to examine the thematic progression in the abstracts, focusing on the features of themes and their employment in the entire discourse.

In this paper, we are interested in analyzing the cohesive devices, particularly the thematic selection and patterning of the selected L2 humanities and science theses abstracts from Nigeria. The comparison between the two fields spells out the organizational peculiarities in terms of the thematic markedness and unmarkedness, on one hand, as well as the progression patterning of themes and rhemes, on the other hand. Apart from discovering the organizational patterns and

${ }^{1}$ Lecturer at the University of Ibadan (Nigeria). 
features of the theses abstracts from humanities and science in the ESL context, this paper provides an insight into how abstracts are informationally developed, as well as into the writer's way of thinking.

\section{Theory and method}

This paper applies both quantitative and qualitative research methods. Both methods are in line with the stated objectives, which include the identification, analysis and comparison of the thematic choices and progression patterns of the theses abstracts from the two broad fields. The data include 60 abstracts from 30 science $\mathrm{PhD}$ theses and 30 humanities $\mathrm{PhD}$ theses, defended at the Premiere University, Nigeria. The abstracts come from the period 2009-2012 and were purposefully selected for the study. Each of these abstracts contains four paragraphs: the introduction, the methodology, the findings and the conclusion, and the analysis is based on this structure.

The theoretical background is based on the Halidayan's Systemic Functional linguistics (2004), Dane (1994), Bloor and Bloor (2001), Eggin (1994) and Zhu (1995). The thematic selection was analysed through the principles of markedness and unmarkedness of clauses at the sentential level of analysis, while the progression patterning was analysed using the following categories: Constant Theme (CT), Constant Rheme (CR), Simple Linear Pattern (SLP), Crossed Pattern (CP), Derived Theme (DT), Derived rheme (DR), Split Theme (ST) and Ruptured Theme (RT).

\subsection{Literature}

Systemic Functional Linguistics, a social semiotic approach to text, provides a threedynamic set of language choices available to speakers in different contexts. First, the interpersonal resources of language enact social roles in the form of the power relations or the power play, which are manifested in the systems of Mood and Modality. Second is the ideational meaning, which construes various experiences of the world (Eggins, 1994); while the third refers to the textual meaning, which subsumes the system of Theme and Rheme. The textual meaning, which is the primary concern of this paper, examines the semantic and the discursive meanings of texts in terms of the theme's markedness and progression.

Earlier, linguists investigated the structure of message in a clause. The foremost scholar, Mathesius (1939) defines Theme as the first part of the sentence, and Rheme as the remaining part of the sentence. In several instances, theme is considered as the structural category realized in the clause-initial position in English (Halliday, 1970). Halliday further adds as follows:

"In English, as in many other languages, the clause is organized as a message by having a special status assigned to one part of it. One element in the clause is enunciated as the theme; then combined with the remainder so that the two parts together constitute a message" (Halliday, 2000: 37-38).

Theme, thus, accounts for the coherence and the internal organization of discourse, through organizing the initiation of the clause and/or by directing the attention of 
the receiver of the message to the parts the sender wishes to emphasize (Dejica, $2005 ; 2009)$. This suggests that the thematic choice of the writer guides the message of the clause. Theme serves as the point of departure of the message (Halliday, 1985: 38). In other words, the initial point of an utterance is of an enormous importance to the clause and also to the text as it influences the hearer/reader's interpretation and understanding of everything that follows. Vasconcellos (1992: 149) says that the theme "signals the relationship between a thought in the speaker's mind and its expression in the discourse".

Rheme, on the other hand, refers to the other information in the clause, i.e. those found outside the theme. It is the remainder of the clause and thus it comes after theme. Rheme has been presented as unfamiliar or new information (Halliday, 1994: 59), but contextual analyses have proven that that may not always be the case, as writers may change the focus for particular reasons (Lombardi Vallauri, 195: 359).

Furthermore, the elements in a thematic structure can be classified into simple, those expressing only one experiential element; or multiple, those expressing more than just an experiential element. Overall, the use of these largely depends on the writer's deliberative choice of a declarative clause or the mood type.

\subsubsection{Theme markedness}

Theme can be either marked or unmarked. The former is used in a declarative clause with a subject in the initial position, while the latter is associated with the unusual choices which have an adjunct as the theme. Unmarked themes usually provide a lower degree of new information than marked themes, which tend to bring in new information, which is why marked themes rely on the context for their meanings (Westergaard, 1986 cited in Manoliu-Manea, 1994: 230). An unmarked theme may thus be the subject of the sentence, while the marked theme may be the non-subject component situated in the initial part of a sentence.

\subsubsection{Thematic progression}

Thematic Progression (TP) was first used by Danes (1974) to refer to the arrangement and the patterning of the theme in texts. It is a clear direction provided by the author to guide the readers through the ideas and areas of the focus in a text. Eggins (1994) further refers to TP as the exchange of information between the Theme and Rheme pairing in a text. He states that the Thematic Progression contributes to the cohesive development of a text, which can strengthen the text's coherence and cohesion. The emphasis here is on the relationship between the theme of a clause, and the themes and the rhemes in the subsequent clauses. The approach to the thematic progression patterning is discourse-oriented, which Danes (1974) refers to as the text's thematic progression. He (1974) defines it as:

"the choice and ordering of utterance Theme, their mutual concatenation and hierarchy as well as their relationship to the hyperthemes of the superior text units (such as paragraph, chapter...) to the whole of text, and to the situation".

Danes (1974) also proposes TP patterns, which include four categories: Simple Linear patterns $(\mathrm{T} 2=\mathrm{R} 1)$, i.e. a new theme (T2) which is the outcome of the 
immediate past Rheme (R1); Constant theme (T2=T1); Derived theme ( $\mathrm{T}=\mathrm{T} 1+\mathrm{T} 2)$ and split Rheme $(\mathrm{R}=\mathrm{R} 1+\mathrm{R} 2)$. However, several scholars have proposed some other relevant patterns for the interpretation of themes in texts (Zhu, 1995; Bloor and Bloor, 2001; Sujatna, 2012, among others). Considering the contributions of each of the scholars above, as well as the peculiarities of the classifications suggested by each, this paper adopts seven categories for the interpretation of the progression patterning in the L2 theses abstracts. They are:

- Constant Theme (CT): the items in the theme of the first clause are employed as the theme of the following clause.

- Constant Rheme (CR): this is the continuous use of the Rheme in sentence 1 as the Rheme in the subsequent sentence(s).

- Simple Linear Pattern (SLP): an item from the Rheme in sentence 1 becomes a Theme in a subsequent clause.

- Crossed Pattern (CP): this is a pattern in which the Rheme of the latter sentence is the Theme of the former sentence.

- Derived Theme (DT): this describes the expression in a theme position, and is cohesively linked to the topic, such that the subsequent themes serve as a sub-theme for the main hypertheme.

- Split Theme (ST): the theme of the first clause is split into several items, each being a theme element in the subsequent clause.

- Ruptured Theme (RT): this is a pattern where the sources of the theme could not directly point to the text before or after it. It is usually adopted by the writer to create a stylistic effect.

In determining the Thematic Progression in the selected disciplines, the occurrences of each these choices was counted in order to reveal the predominantly used pattern(s) at the sentential and the discourse levels.

\section{Data analysis}

This section examines the thematic selection in the selected theses abstracts. The analysis is done at the sentential level, in terms of the theme's markedness and unmarkedness.

\subsection{Marked and unmarked themes in L2 humanity-based and science-based theses abstracts}

Table 1 represents the number of sentences contained in the two parts of the corpus respectively. The results for the four paragraphs of the theses abstracts are given individually. 


\begin{tabular}{c|c|c|c|c}
\multirow{2}{*}{ Paragraphs } & \multicolumn{2}{|c|}{ HUMANITIES } & \multicolumn{2}{c}{ SCIENCE } \\
\cline { 2 - 5 } & MARKED & UNMARKED & MARKED & UNMARKED \\
\hline 1 & 31 & 97 & 20 & 92 \\
\hline 2 & 7 & 150 & 14 & 200 \\
\hline 3 & 40 & 178 & 30 & 213 \\
\hline 4 & 14 & 81 & 4 & 52 \\
\hline TOTAL & $\mathbf{9 2}$ & $\mathbf{5 0 6}$ & $\mathbf{6 8}$ & $\mathbf{5 5 7}$ \\
\hline SUM TOTAL & \multicolumn{2}{|c}{$\mathbf{5 9 8}$ CLAUSES } & \multicolumn{2}{c}{$\mathbf{6 2 5}$ CLAUSES }
\end{tabular}

Table 1. Distribution of clauses in the abstracts

Table 1 above shows that a total number of 598 clauses are used in the humanities theses abstracts, while 625 clauses are used in the science theses abstracts. A slightly larger number of sentences used in the latter may be attributed to the demand for more sentences in the methodology and the findings sections of the science abstracts.

Tables 2 and 3 show the distribution of marked and unmarked themes in the selected abstracts, respectively. The results for the four paragraphs of the abstracts are given individually.

\begin{tabular}{c|c|c|c|c|c}
\multirow{2}{*}{ Paragraph } & \multicolumn{2}{|c|}{ HUMANITIES } & \multicolumn{2}{c|}{ SCIENCE } & \multirow{2}{*}{ TOTAL } \\
\cline { 2 - 5 } & FREQUENCY & $\mathbf{\%}$ & FREQUENCY & $\mathbf{\%}$ & \\
\hline 1 & 97 & 51.3 & 92 & 48.7 & $\mathbf{1 8 9}$ \\
\hline 2 & 150 & 42.9 & 200 & 57.1 & $\mathbf{3 5 0}$ \\
\hline 3 & 178 & 45.5 & 213 & 54.5 & $\mathbf{3 9 1}$ \\
\hline 4 & 81 & 60.9 & 52 & 39.1 & $\mathbf{1 3 3}$
\end{tabular}

Table 2. Distribution of unmarked themes in the two fields

\begin{tabular}{c|c|c|c|c|c}
\multirow{2}{*}{ Paragraph } & HUMANITIES & \multicolumn{2}{c|}{ SCIENCE } & \multirow{2}{*}{ TOTAL } \\
\cline { 2 - 5 } & FREQUENCY & $\mathbf{\%}$ & FREQUENCY & \% & \\
\hline 1 & 31 & 60.8 & 20 & 39.2 & $\mathbf{5 1}$ \\
\hline 2 & 7 & 33.3 & 14 & 66.7 & $\mathbf{2 1}$ \\
\hline 3 & 40 & 57.1 & 30 & 42.9 & $\mathbf{7 0}$ \\
\hline 4 & 14 & 77.8 & 4 & 22.2 & $\mathbf{1 8}$ \\
Table 3. Distribution of marked themes in the two fields
\end{tabular}

In Tables 2 and 3 above we can see that, in both the categories analyzed, unmarked themes are most often used for conveying specific information and for proving arguments to the readers. Unmarked themes aid the readers' interpretation of the message through a subject plus verb declarative clause. Some examples are given below:

Datum $7 \mathrm{a}(3)$ science

a. Five $L A B$ (Lactic Acid Bacteria) species were identified, while seven species of bacterial uropathogens with resistance to at least one antibiotic were identified.

b. The entire $L A B$ produced acetaldehyde, acetone ethyl-acetate, 2-butanone and ethanol but, weissella confura strains produced the largest quantities of ethanol. 
In Paragraph 3 of the datum 7 above, the two italicized unmarked themes in the paragraph ('Five LAB (Lactic Acid Bacteria) species' and 'The entire LAB') describe the uropathogens isolated in Dairy foods.

Datum $4 \mathrm{~b}(2)$ humanities

c. All the texts are an expression of disenchantment with postcolonial Morocco and its neo-colonialist leaders.... The author portrays ...emigration to Italy. The text depict characters ... and deconstructing geographies.

The unmarked theme above are given in subject-oriented declarative clauses describing the global geography in the analysis of emigration and a definition of a contemporary piece of travel writing that incorporates facts and fiction.

Data 7 and 4 presented above are instances of the nominal-headed subjects of the declarative clause. However, there are a few instances in the abstracts in which pronominals were used as themes, locating their references from the antecedents. Examples include the following:

Datum 14b(3) humanities

d. The Nigerian military has contributed immensely towards the sustenance of stable peace in Liberia. It contributed all the ...in Liberia. It has also provided electricity....

The referents in the thematic choices of the second and the third sentence above would be vague without the nominal referent in the first clause. In other words, the thematic choice of the last two pronominals suggests a progression pattern with the subject-theme in the first clause. The distribution of unmarked themes in the four paragraphs of the selected abstracts differs significantly. The analysis reveals that unmarked themes prevail (usually in declarative clauses) in paragraphs three and two of the abstracts. The analysis suggests that these two paragraphs provide both new and given information unlike the other paragraphs in the abstracts. It is within these paragraphs that the authors, using the declarative themes, provide the synopsis of their research findings or the results, as well as the methods of the data analysis.

Unmarked themes in scientific disciplines are more frequent than in humanities. One reason is the scientific reliance on the description of various experiments, treatments and instruments used in the research. Furthermore, in certain contexts, unmarked themes are realized through the existential 'there'. This theme is non-referential. In this case, the theme occupies the subject position but does not have a referent or an antecedent in the present discourse. Systemic grammar is of the opinion that the systemic choice of 'there' as the theme in a clause is a deliberate attempt to realize an ideational meaning and, thus, a topical theme. Examples of existential themes include the following: 
Datum $14 \mathrm{a}(4)$ humanities

e. There is the conviction that 'bata' changes mood, promotes the scope and popularized performance.

Datum $4 \mathrm{a}(3)$ science

f. There were significant differences... among the progenies for FRY, FSW,NTR and HI...

The analysis above presents the theme and the subject as the same item, which aids to the continuity of the topic of the thesis. It also helps the authors to convey their main arguments, thereby assisting the readers in understanding the information.

Table 3 also shows the thematic distribution of a group of clauses other than the subject in a declarative clause. These clauses are realized as marked themes. The clauses in this category include the adverbial group and the prepositional phrases functioning as adjuncts in the clause. The presence of a marked theme in the clause signals "some kind of specific contextual pressure at work, often associated with a change of textual frame, rather than the continuity of topic of discourse or text" (Chapman and Routledge, 2009: 230). In the selected abstracts, both adverb-headed and preposition-headed adjuncts are present. Let us consider the following:

Datum1b(1) science

g. However, the increasing level of poverty could impact negatively on agriculture, especially fish farming. Though, there is prevalence of information on poverty.

Datum 5(3) science

h. Moreover, different phonological processes, such as nasalization... Conversely, contact with other languages, especially Yoruba and Edo... By Contrast, the Owon varieties are $81.0 \%$ cognate... Therefore, they are classified together as dialects...

In the examples above, the authors deliberately use unusual constructions to emphasize the meaning. They are used to accentuate particular information that has previously been stated or mentioned by the writer. The writer of Datum $1 b(1)$, for instance, uses 'however', an adversative, to express a semantic relationship between the discourse stretches on the poverty status in Nigeria. Likewise, 'moreover' in datum 5 above serves as the additive to the former argument; 'conversely', 'by contrast' and 'therefore' are used to mark a reversal from the earlier arguments, as well as the comparison and the connection of ideas, respectively. Green et al. (2000: 105) emphasize that these connectors introduce a new topical referent or recall a referent with a relatively remote antecedent. Apart from the adverb-headed themes, there are also occurrences of a preposition-headed theme in the abstracts. Let us consider the following examples from the data:

Logos et Littera: Journal of Interdisciplinary Approaches to Text 
Datum a(3) science

i. After antioxidant supplement in hypertensives, mean body weight ...were significantly lower than the corresponding baseline levels.... In rabbits, mean TC, LDL-C, HDL-C and TG increased in group 3

Datum 14a (3) humanities

j. In a developed country, break dance is indeed an extension of 'bata' forms in performance. Before now, 'bata' operated only in union....

The examples above illustrate the use of the two main categories of prepositions - the prepositions of place, answering the question 'where', and the prepositions of time, answering the question 'when'. Here, the former indicate the position or the location of a finding, and the latter refer to the description of the time settings. The examples above include the prepositional phrases 'in Rabbit' and 'in a developed country', as well as 'after antioxidant supplement in hypertensives,' and 'before time'.

All these categories of marked themes are used for emphasis. As can be seen from Table 3 above, marked themes are more frequent in humanities than in science abstracts. Meticulous attention is paid to Paragraph 3 (the research findings), as well as Paragraph 1 (the introductory paragraph), where there is a dominant use of marked themes. Humanities abstracts pay substantial attention to circumstantial elements, unlike science abstracts, which accounts for a remarkably larger presence of the adjunct-based themes in their research findings, conclusion and introductory paragraphs, respectively. Marked themes, however, are slightly more present in Paragraph 2 of the science abstracts. This difference is a result of the 'other' information required to support the claims in the methodology paragraph.

\subsection{Thematic progression in Humanity and Science-based disciplines}

The results below reveal seven progression patterns of themes in the data.

\begin{tabular}{c|c|c|c|c|c|c|c|c|c|c|c|c|c|c|c} 
& $\mathbf{C T}$ & $\mathbf{\%}$ & $\mathbf{C R}$ & $\mathbf{\%}$ & $\mathbf{S L P}$ & $\mathbf{\%}$ & $\mathbf{C P}$ & $\mathbf{\%}$ & $\mathbf{D T}$ & $\mathbf{\%}$ & $\mathbf{S T}$ & $\mathbf{\%}$ & $\mathbf{R T}$ & $\mathbf{\%}$ & TOTAL \\
\hline HUMANITIES & 97 & 58.1 & 2 & 1.2 & 32 & 19.2 & 2 & 1.2 & 10 & 6.0 & 1 & 0.6 & 22 & 13.2 & $\mathbf{1 6 7}$ \\
\hline SCIENCE & 53 & 40.2 & 8 & 6.1 & 24 & 18.2 & 8 & 6.1 & 17 & 12.9 & 1 & 0.8 & 21 & 15.9 & $\mathbf{1 3 2}$
\end{tabular}
Table 4. Distribution of the seven patterns of thematic progressions in the abstracts

\begin{tabular}{c|c|c|c|c|c|c|c|c|c|c|c|c|c|c|c|c}
$\begin{array}{c}\text { Thematic } \\
\text { progression }\end{array}$ & $\mathbf{1}$ & $\mathbf{2}$ & $\mathbf{3}$ & $\mathbf{4}$ & $\mathbf{5}$ & $\mathbf{6}$ & $\mathbf{7}$ & $\mathbf{8}$ & $\mathbf{9}$ & $\mathbf{1 0}$ & $\mathbf{1 1}$ & $\mathbf{1 2}$ & $\mathbf{1 3}$ & $\mathbf{1 4}$ & $\mathbf{1 5}$ & Total \\
\hline CT & 7 & 4 & 3 & 11 & 4 & 10 & 7 & 6 & 9 & 5 & 6 & 12 & 3 & 9 & 4 & $\mathbf{9 6}$ \\
\hline CR & 0 & 0 & 00 & 0 & 0 & 0 & 0 & 0 & 0 & 0 & 1 & 0 & 0 & 0 & 0 & $\mathbf{1}$ \\
\hline SLP & 3 & 0 & 5 & 2 & 4 & 1 & 2 & 1 & 2 & 3 & 1 & 1 & 2 & 1 & 3 & $\mathbf{3 1}$ \\
\hline CP & 0 & 1 & 0 & 0 & 0 & 0 & 0 & 0 & 0 & 0 & 0 & 0 & 0 & 0 & 0 & $\mathbf{1}$ \\
\hline DT & 0 & 0 & 3 & 0 & 0 & 0 & 0 & 0 & 1 & 0 & 0 & 0 & 0 & 0 & 0 & $\mathbf{4}$ \\
\hline ST & 0 & 0 & 0 & 0 & 0 & 0 & 0 & 1 & 0 & 0 & 0 & 0 & 0 & 0 & 0 & $\mathbf{1}$ \\
\hline RT & 0 & 1 & 1 & 7 & 0 & 5 & 1 & 5 & 2 & 1 & 0 & 2 & 2 & 1 & $\mathbf{2 9}$ \\
\end{tabular}
in the humanities abstracts 


\begin{tabular}{c|c|c|c|c|c|c|c|c|c|c|c|c|c|c|c|c}
$\begin{array}{c}\text { Thematic } \\
\text { progression }\end{array}$ & $\mathbf{1}$ & $\mathbf{2}$ & $\mathbf{3}$ & $\mathbf{4}$ & $\mathbf{5}$ & $\mathbf{6}$ & $\mathbf{7}$ & $\mathbf{8}$ & $\mathbf{9}$ & $\mathbf{1 0}$ & $\mathbf{1 1}$ & $\mathbf{1 2}$ & $\mathbf{1 3}$ & $\mathbf{1 4}$ & $\mathbf{1 5}$ & total \\
\hline CT & 4 & 6 & 6 & 2 & 2 & 3 & 2 & 3 & 4 & 4 & 1 & 2 & 10 & 1 & 3 & $\mathbf{5 2}$ \\
\hline CR & 0 & 1 & 0 & 0 & 0 & 1 & 1 & 2 & 1 & 1 & 0 & 1 & 0 & 0 & 0 & $\mathbf{8}$ \\
\hline SLP & 4 & 1 & 2 & 2 & 1 & 1 & 2 & 2 & 4 & 2 & 0 & 2 & 0 & 0 & 1 & $\mathbf{2 4}$ \\
\hline CP & 1 & 1 & 0 & 0 & 1 & 0 & 0 & 0 & 1 & 1 & 0 & 2 & 1 & 0 & 0 & $\mathbf{8}$ \\
\hline DT & 2 & 0 & 2 & 6 & 2 & 0 & 0 & 1 & 2 & 0 & 0 & 0 & 0 & 0 & 0 & $\mathbf{1 5}$ \\
\hline ST & 0 & 0 & 0 & 0 & 1 & 0 & 0 & 0 & 0 & 0 & 0 & 0 & 0 & 0 & 0 & $\mathbf{1}$ \\
\hline RT & 0 & 1 & 0 & 3 & 2 & 5 & 0 & 0 & 0 & 0 & 3 & 1 & 0 & 0 & 1 & $\mathbf{1 6}$
\end{tabular}

Table 5b. Distribution of the seven patterns of thematic progressions

in the science abstracts

Constant theme: Based on the results presented above, it is clear that seven thematic progression patterns are used in the data. Among these patterns, a constant theme pattern is the most used progression in both the categories. It is frequently used in cases when many clauses share the same theme, and also to closely connect the previously used theme with the preceding arguments in the abstracts. It is used more often in the humanities abstracts $(58.1 \%)$ than in the science abstracts (40.2\%). Below are examples from the data.

Datum $4 \mathrm{~b}(2)$ humanities

a. These texts are selected because they portray legal and illegal movement of people... The texts are content analysed... All the texts are an expression of disenchantment with postcolonial Morocco and its neo-colonialist leaders.

Datum 15a(1) science

b. Millet and Castor are two important tropical crops with numerous nutritional and industrial uses. These crops are presently dried using the traditional sun drying method.

Datum $7 \mathrm{a}(2)$ humanities

c. Iwa is fundamental to human existence and social relations. It has profound value, as evident in the saying...

The three examples above point to a consistency in thematic representation. A common characteristic of such a consistency is that it helps the readers to get the main theme quickly, which enables easier understanding of the subsequent arguments in the clause. Also, if the main idea lurks in the theme, it definitely helps the readers grasp the idea around the topic. In the examples above, there are 3 categories of CT. The first example (datum $4 \mathrm{~b} 2$ ) is an instance of the use of varied modifiers: 'these', 'the' and 'all the', respectively. They modify a single headword 'text', in the three clauses. The second example has two synonymous CT, that is, 'Millet and Castor', which are both crops - hence the use of 'these crops'. This synonymous pattern is a stylistic choice used to avoid unnecessary repetitions of the lexical words. From the third example above, it is clear that 'Iwa', a nominal entity, is later realized as 'it', a pronoun in the subsequent clause. From all the examples and 
their analyses, we may conclude that the Constant theme is an efficient thematic patterning which was mostly used by the second language theses writers in projecting the main arguments in the body of the abstracts. Table 5 above reveals that CT is widely used in Paragraph 3 (the findings/result paragraph) and 2 (the methodology paragraph) of the abstracts, respectively, although it is slightly more present in the humanities abstracts than in the science ones. The few occurrences of this pattern in Paragraphs 1 and 4 are used to emphasize the central ideas in the introductory (Paragraph 1) and the concluding (Paragraph 4) paragraphs of the selected abstracts.

Simple Linear Progression (SLP): this is the second most frequent progression pattern in the abstracts. It refers to the pattern in which the rheme of a previous clause becomes the theme of the subsequent clause. SLP is used in 32 humanities abstracts and 24 science abstracts. A few examples are given below:

Datum 5a(3) humanities

a. Akokoid speech forms have undergone systematic changes over time. These changes have occasional phonological and lexical variations within the group.

Datum 4(2) humanities

b. The study adopts travels, postcolonial theory and psychoanalysis in examining the selected works. These themes permit a wide perspective in the analysis of...

c. The study uses the tents of ...as methodology in the interpretation of 'Les Yeux baisses, Labyrinthe des sentiments and Au plays'. These texts are selected because they portray...

Datum $4 \mathrm{a}(2)$ science

d. Bulked Segregant Analysis was used to investigate the SSR markers associated with .... The identified SSR markers were used to select EB-HY genotypes....

Datum 8a(2) science

e. The separation was carried out by the participants for a period of 3 months after which a post-intervention questionnaire was administered to access the impact of mobilization in their practices. Practices scores were computed based on....

f. They were mobilized in a week-training to separate their household solid waste.... The separation was carried out by the participants for a period of 3 months.

In the excerpts, the rhemes of the first clause above, 'Les Yeux Baisse, the SSR markers, practices and separate their household waste', become the themes in the subsequent clauses. Looking through several examples identified above, it is clear that SLP provides a background for the build-up of information. The analysis reveals that SLP is mostly used in the methodology and the findings paragraphs. Generally, 
SLP represents a sequence of a items, a process and an event which aids the organization of a text. Such an organization, derived from both the thematic and the rhematic arrangements, characterizes L2 writing as successful in terms of coherence (Bloor and Bloor, 1992; Wei, 2014). The thought flow process, as exemplified in the data above, also helps the readers understand the purpose of the text. Wang (2007: 167) argues that when a text is not coherent "there is a clear signpost directing the reader, who therefore cannot easily follow the progression of an idea or argument". SLP points to consistency and exerts an impact on the development of information in the argumentation, where the arguments are arranged in a meaningful way to achieve their purpose (Nwogu and Bloor, 1991). The fact that the examples above draw from the rheme of a previous clause for the theme of the following clause, suggests an embedded logical and elaborate argument of detailed messages.

The analyzed humanities abstracts allow for some flexibility in style and voice, characteristic of interpretive writing, which is backed up with specific arguments and examples from the data. Through this, writers project their ideas or arguments into their writing. On the other hand, science abstracts have a distinctive style of presenting and recording data in a precise manner, hence avoiding a certain flowery language patterning, specific language rhetoric and metaphors which are usually found in the humanities' writings.

Ruptured theme (RT): this is the third most occurring pattern in the abstracts. It occurs where a syntactic element in the thematic position failed to create a texture. RT usually appears in a form of the anticipatory subject 'it' or the existential subject 'there'. However, from the analysis, the most occurring RT among the identified forms is the existential subject 'there'. Let's look at the following examples:

Datum $4 b(3)$ science

a. There were significant differences in the deffured 2261.7(G1)2805.7(G8)....

b. There were no significant differences in packed cell (\%) 35.7(Gi-36.9)....

Datum 15a(1) science

c. There is dearth of information on the drying behavior of castor, while that of millet is limited to sorption of a new varieties.

Datum $2 \mathrm{~b}(1)$ humanities

d. There have been efforts at research into biblical literature, particularly from the socio-historical and doctrinal perspective.

Datum 7a(4) humanities

e. There is need for moral re-orientation in contemporary Yoruba society, which premised on the virtue of 'iwa' as it pivotal in traditional Yoruba religious philosophy.

The above samples taken from the abstracts feature the existential 'there'. However, the use of 'there' above is different from its usage as a place adverb. Here, 
it has no locative meaning and carries no emphasis (Rediscover grammar, 2003). The existential 'there' above functions as a dummy subject, in this case - a dummy theme fulfilling a mere grammatical function of the subject, but not playing a semantic role. The analysis reveals that both the categories of the abstracts make use of the existential theme 'there' to mark a representation element (Downing and Locke, 2006). A further analysis of the data shows an equal occurrence of RT in the humanities and the science abstracts. Its presence is significant in Paragraph 1, where it is used to promote background information on the subject matter, as well as in Paragraph 3, where it is used to mark a statistical hypothesis of certain concepts.

Derived Theme (DT): this is the fourth pattern of thematic progression in the abstracts. The Table above reveals that this type of progression is mostly used in the science abstracts. It is a pattern that provides a high degree of coherence and a smooth flow of information on the subject matter, which is usually the hypertheme. Some examples are given below.

Datum $3 b(3)$ humanities

a. These three structures were arranged in a manner that got the blog readers into believing that they had made appropriate choices of responses....

b. The surface structure contained nationalist ideologies. The dialogical structure engaged the blog readers in imagined conversation. The schematic structure defined the canonical order of the discourse.

Datum $5 a(3)$ science

c. Lead was most predominant with significantly higher concentration at the study site.... Post -cropping soil lea concentration were reduced significantly by 39.2 and $38.0 \%$ in soil....

Datum $4 \mathrm{~b}(2)$ science

d. Three experiments were conducted using a complete randomized design. In experiment 1, 32GG aged 24 weeks...were randomly allocated.... In experiment 2, $36 \mathrm{GG}$ aged 12 weeks...were randomly allocated. In experiment 3, 12 pelleted diets containing four different $\mathrm{CP}$ and their energy level were fed.

In DT, the first theme is regarded as the 'hypertheme', while the subsequent themes in the following sentences are derived from that hypertheme. The hypothesis in the examples above is realized through the forms 'these three structures', 'lead', and 'three experiments', respectively. For instance, the derived themes for the first hypertheme above are 'the surface structure', 'the dialogic structure' and 'the schematic structure'. The three examples above show that the DT progression is a simple test of consistency of an argument regarding the specific subject matters.

Cross-pattern progression (CP): this is another progression pattern in academic writing, but it is rarely used in the L2 academic abstracts. However, a few

Logos et Littera: Journal of Interdisciplinary Approaches to Text 
of its occurrences suggest that it is more present in the science abstracts. Some examples are given below.

Datum 9a(1) science

a. The role of pair education in promoting nutrition education among adolescent has been fully investigated in Nigeria. The study therefore assessed the effects of pair education on nutrition and reproductive health....

\section{Datum 12a(1) humanities}

b. This study was anchored on the uses and gratification theory and cultivation theory. The survey research method was adopted for the study.

It is clear from the above examples that CP in the initial example was used inbetween the 'gap' observed in previous research and the objective of the present study. This implies that, if there had not been a gap in the research, there would not have been a need for the present research. The second example, on the other hand, shows the relationship between the former theme in Clause 1 and the rheme in Clause 2, thereby aiding the coherence of the entire text. In sum, CP occurs only between Paragraphs 1 and 2 of the abstract and, by implication, it links the gap, the objectives and the theoretical framework of the selected theses.

In addition to the previously discussed thematic progression patterns in the selected theses, the analyzed texts reveal that other patters are scarcely present. These include the Constant Rheme (CR), Split Theme (ST), and Derived Rheme (DR). Constant Rheme pattern makes the rheme of a clause continuous in the subsequent clauses. This suggests that an idea, concept or information in the abstract lurks in the rheme rather than in the theme of a clause. Unfortunately, the abstracts explored in this study do not favour CR compared to CT. The implication of this is that the readers will not have to struggle to get the main ideas from the clause. Let us examine three CR patterns found in the data:

\section{Datum 2a(3) science}

a. Furthermore, $61.7 \%$ urban and $67.0 \%$ rural respondents indicated community agitation as a major case of establishment of community project.

Datum $2 b(2)$ science

b. The experimental group (EG) comprised of 312 Nurses in University of Calabar teaching Hospitals and General Hospitals, Calabar, while the control group (CG) consisted of 310 Nurses in University of Uyo teaching hospital and Saint Luke's hospital Uyo.

c. Stratified random sampling technique was employed in selecting Nurses from the five nursing cadres, in each group.

The analysis reveals more uses of CR in the science than in the humanities abstracts.

Logos et Littera: Journal of Interdisciplinary Approaches to Text 
Another scantily present pattern in the data is the split theme. The primary aim of this type of progression is to organize information into subordinate parts, thus, scaffolding the content of the longer stretches of texts. Examples follow:

Datum 5a(3) science

a. The CPW and MSW at $40 \mathrm{t} /$ ha increased DMA of maize by $95.4 \% \ldots$.

b. The MSW at 40t/ha significantly reduce soil lead concentrations in the screen-house....

Datum 8b(3) humanities

c. Parents' education...; parents' occupation...; parents' income... and parents' involvement...made significant relative contribution to academic achievement in English language. Parental involvement...made significant relative contribution to academic achievement in mathematics.

In the extracts above, the split theme in the second clause is the main theme of the first clause. This form of pattern is rarely used in the L2 abstracts because there is more than one subject matter or idea to be developed.

Apart from the seven thematic progression patterns identified and exmplified above, there are some other 'unpatterned themes' in the theses abstracts analyzed which do not directly relate to any of the above-mentioned models.

In summary, the thematic selection and progression pattern analyzed above have revealed the coherence status achieved through a thematic organization in both the humanities and the science L2 abstracts. The initial analysis of the thematic selection present unmarked themes as the most preferrable in both types of abstracts, though it is more frequently used in the science abstracts than in the humanities abstracts. This suggests that the abstract writers deliberately foreground the information in the unmarked position of the clause. On the other hand, the subsequent analysis of the progression pattern presents the flow of a message and a close connection of information in the data.

The constant theme was the dominant thematic progression type, followed by the simple linear progression, the ruptured theme, the derived theme, the crosspattern theme, the constant rheme and the split theme, respectively.

\section{Conclusion}

For the purpose of this study, we built a small corpus of the theses abstracts from humanities and science. The objectives were to analyze theme markedness and also to reveal the thematic progression patterns in both the fieldw. The foregrounding of unmarked themes, as well as the predominant choice of the constant theme and the simple linear progression in both the categories, confirm Thompson's assertion (2004: 165) that themes need to signal what the speaker (the writer) thinks is a suitable starting point, and also signals the maintenance or progression of what the text is about.

The analysis and the results presented here can enhance the understanding of text organizations in L2 science and humanities academic writing. 


\section{References}

Bloor, T. and Bloor, M. The functional analysis of English. A Hallidayan approach. Beiging: Foreign Language Teaching and Research Press and Edward Arnold (Publishers) Limited, 2001.

Danes, F. "Functional sentence perspective and the organization of the text". Papers on functional sentence perspective. Ed. F. Danes. The Hague: Mouton, 1974.

Dejica, D. "Identifying and analyzing thee-rheme relations for discourse production and translation". Romanian Journal of English Studies. Timisoara: Editura Universitatii de vest. 6. (2009): 128-136.

Dejica, D. "Towards a new model for the identification of Theatic information in discourse". Comunicare Profesional ta si traductologies. Eds. R. Superceanu and D. Dejica .Timisoara: Universitatea Politehnica. 2005. 103-111.

Eggins, S. An introduction to functional Linguistics. London: Printer Publishers, 1994.

Green, Christopher F., Elsie R. Christopher, Jaquenlin Lam and Kam Mei. "Thematic Progression in professional and popular medical texts". Functional and systemic linguistics: Approaches and uses. Ed. E. Ventola. Berlin Mouton de Gruyter, 1991. 369-384.

Halliday, M.A.K. Halliday's introduction to fuctional grammar ( $4^{\text {th }}$ ed). Revised by C.M.I.M. Matthiessen. New York: Routledge, 2014.

Halliday, M.A.K. "On the transition from child tongue to Mother tongue". Australian Journal of Linguistics, 3 (1983): 201-216.

Halliday, M.A.K. "Language Structure and Language Function". New Horizon in Linguistics. Ed. J. Lyons. Pergiu Harondsworth (1970): 140-165.

Halliday, Michael and Hassan Ruqaiya. Cohesion in English. London: Longman Publishing, 1976.

Lombardi Vallauri E. "Linguistic Features of persuasion in advertising". Lingua Nostra. 2.3 (1995): 41-51.

Manoliu-manea, M. Discourse and Pragatic constraints on Grammatical choices: A grammar of Surprises. Amsterdam: Elsevier, 1994.

Mathesius, Vilem. “On so-called functional sentence perspective”. Slovo a Slovensnost 7 (1939): 169-180.

Sujatna, Eva. "Applying Systemic functional Linguistics to Bahasa Indonesia Clauses". International Journal of Linguistics. 4.2 (2012).

Thompson, G. Introducing Functional Grammar (3rd Ed.). Abingdon: Routladge, 2014.

Vasconcellos, J. "The theme as message onset: Its structure and characteristics". Linguistics, 30.1 (1992): 147-143.

Wang , Lixia. "Theme and Rheme in the thematic organization of text: Implication for teaching academic writing". Asia EFL Journal. 9.9 (2007): 88-101.

Wei, J. "Theme and thematic progression in Learner English: A literature review". Colombian Applied Linguistics Journal. 16.1(2014): 67-80.

$\mathrm{Xu}, \mathrm{S} . \mathrm{H}$. "Theme and Rheme". Foreign Language Teaching and Researching. 1 (1982): 1-9.

Zhu, Y.S. "The pattern of thematic progression analysis and discourse". Foreign Language Teaching and Rsearching. 3 (1995): 6-12.

Logos et Littera: Journal of Interdisciplinary Approaches to Text 